\title{
Comorbidities and Care Practices of Diabetic Patients
}

\author{
Rahaman KS ${ }^{1 *}$, Majdzadeh $\mathbf{R}^{2}$, Naieni $\mathbf{K H}^{3}$ and \\ Raza $\mathbf{O}^{3}$ \\ ${ }^{1}$ School of Public Health, International Campus, Tehran \\ University of Medical Sciences, Iran \\ ${ }^{2}$ Department of Epidemiology and Biostatistics \& \\ Knowledge Utilization Research Center, School of Public \\ Health, Tehran University of Medical Sciences, Iran \\ ${ }^{3}$ Department of Epidemiology and Biostatistics, School \\ of Public Health, Tehran University of Medical Sciences, \\ Iran \\ *Corresponding author: Rahaman KS, School of \\ Public Health, International Campus, Tehran University \\ of Medical Sciences, Tehran, Iran
}

Received: March 16, 2017; Accepted: July 07, 2017; Published: July 14, 2017

\section{Abstract}

Introduction: Diabetes mellitus causes millions of deaths every year around the globe posing serious threat to public health. Death occurs mostly due to co-morbidities and complications resulting from diabetes. Our study was designed with the aim to observe the co-morbidities and practices regarding care of diabetes among patients with type 2 diabetes mellitus.

Methods: In 2016, we conducted this quantitative cross-sectional study by recruiting suitable type 2 diabetic patients conveniently forms the outpatient department of BIRDEM hospital, Dhaka. Patients more than 18 years old have been included in this study. Pre-tested, structured questionnaire was used to gather necessary information. Co-morbidities were identified by patient's medical history. Univariate and bivariate analysis has been done to identify significant factors associated with practices.

Results: Majority of the patients (75\%) were suffering from co-morbidities. Respiratory illnesses, cardiovascular diseases particularly hypertension and renal diseases were the most commonly found co-morbidities. The mean practice score was 16.89 (95\% Cl for mean 16.25-17.53). Poor practice level were observed among $30 \%$ of the respondents. Gender $(p=<0.001)$, marital status $(p=<0.001)$, habitats $(p=<0.001)$, education $(p=0.001)$ and educational program on diabetes $(p=<0.001)$ were the most associated factor with care practices diabetes.

Conclusion: Poor practice levels were found in this cohort with several associated factors. Physicians counselling and motivation as well as robustly designed educational program encouraging self-care of patients can be effective tool to deal with co-morbidities and existing complications of diabetes.

Keywords: Co-morbidities; Practices; Diabetes mellitus; Type 2

\section{Introduction}

Diabetes mellitus is a major public health issue with increase in global prevalence taking place predominantly in developing countries particularly in Southeast Asians [1,2]. It is also counted as major threat of death worldwide [3] and projected to be the $7^{\text {th }}$ leading cause of death in 2030 [4]. Diabetes was the direct cause of 1.5 million deaths and additional 2.2 million deaths occurred due to increased risk of co-morbidities linked with hyperglycemia estimated in 2012 [4,5]. It is estimated that most diabetic adults are suffering from at least 1 chronic illness [6] and $40 \%$ of them have at least 3 co-morbidities [7].

The prevalence of diabetes is increasing drastically in Bangladesh during past few years [8]. According to the recent report, 7.1 million adults are suffering from diabetes and within 2040 the projected figure would be nearly two folds [9]. Prevalence is higher in urban areas (8.1\%) [10]. Moreover, Bangladesh is among the top ten countries in the world having highest number of diabetic individuals [9]. Diabetes induces many complications (acute or chronic) over time in most cases [11]. Diabetes is the prime cause of many systemic diseases in high-income countries [9] and risk of death among diabetics is twice than non-diabetics. The high prevalence of diabetes in Bangladesh will consecutively increase the number of people with diabetic complications and co-morbid conditions $[13,14]$. Lack of awareness and definite care will influence patient's quality of life imposing economic burden [15].
Prominent health care and significant amount of health care cost are required for diabetic patients with multiple chronic conditions $[7,16,17]$. Necessary intervention is needed otherwise the care expenditure of diabetes will have negative impact on health care system [18]. Therefore, care practices of patients regarding diabetic complications and related co-morbidities are necessary. This primary study can be of help designing future interventional strategies.

\section{Objectives}

This particular study was carried out to figure out about what extent diabetic patients are suffering from other co-morbid conditions, the level of practices regarding complications of diabetes care and its associated factors in Dhaka, Bangladesh.

\section{Materials and Methods}

A cross-sectional study was carried out on suitable 425 type two diabetic patients. We recruited patients conveniently from outpatient department of BIRDEM hospital, a referral hospital in Dhaka, Bangladesh particularly for diabetic patients. The study period was from July 2016 to September 2016. Type-2 diabetic patients (both male and female) older than 18 years coming to follow up or seeking general treatment in medicine outpatient departments with at least 1 year past the initial diagnosis of diabetes were included. Exclusion criteria were pregnant women, emergency care patients, and inpatients. Data were collected by experts and trained data 
collection team. The questionnaire did not have of any questions which can disclose the identity of patients or their treating doctors. Ethical considerations were fulfilled by obtaining verbal consent and maintaining the confidentiality.

\section{Questionnaire design}

A pre-tested structured, bilingual questionnaire was developed comprised both open and close ended questions. Patients were interviewed face-to-face by data collection team. The patients were free to choose the language for answering the questionnaire (English and Bengali). The questionnaire was divided into few main categories such as demographic information, socioeconomic information, diabetes and co-morbidity history and practice related information. Medical records were reviewed to identify diagnosed co-morbid conditions, recent Random Blood Sugar (RBS) report and Hemoglobin A1C (HbA1C) levels (within 6 months of the inclusion) retrospectively.

\section{Statistical analysis}

Collected data were then entered for analysis to Statistics Package for Social Science (SPSS) version 22 for Windows. Descriptive statistics and frequency distributions were used to describe participant characteristics. Principal Component Analysis (PCA) method was used to determine respondent's socioeconomic status by calculating patients fixed assets and employment status. One way ANOVA was used to compare means for variables with more than two categories. A ' $p$ ' value less than 0.05 was taken to define significant relationship among variables.

\section{Results}

A total of about 425 diabetic patients were selected randomly in this study. The table below Table 1 shows the total number of participants by age group and number of female with percentage according to the age group. Among the participants attended in the study, males were 234 (55.1\%). Most of the participants were between age group of $26-45$ years $(n=231 ; 54.4 \%)$. The mean \pm SD age of the study participants was $43.45 \pm 11.81$ years (range $21-82$ years). The graphical pictures show that males were affected by type 2 diabetes more than females.

Majority of the participants ( $\mathrm{n}=190 ; 44.7 \%)$ were urban habitats and most of them were married $(n=366 ; 86.1 \%)$. Number of participants belonging from low socioeconomic status were higher $(\mathrm{n}=145 ; 34.1 \%)$. The mean duration of diabetes was $9.16 \pm 6.03$ years. One hundred and seventy four (40.9\%) patients had family history of diabetes. One hundred and sixty four (38.6\%) participants have attended educational programs on diabetes only once during the disease period. The consultation time was given between 5 to 10 minutes reported by most of the participants $(n=150 ; 58.8 \%)$. One hundred and twelve (26.4\%) patients were using herbal medication beside their regular prescriptions. Details are shown in Table 2.

Nearly all patients were on medication $(\mathrm{n}=422 ; 99.3 \%)$ and nearly half of the participants were receiving combined treatment with diet and insulin ( $\mathrm{n}=204,48 \%)$. Three hundred and two (71.1\%) patients have visited dietician for advice on their diet for diabetes. Nearly $70 \%$ percent $(n=297)$ of respondents monitor their blood glucose from hospital. Only $3.8 \%(n=16)$ respondents reported that they monitor their blood glucose by themselves. The mean Random Blood Glucose

Table 1: Age and Gender distribution of the participants.
\begin{tabular}{|c|c|c|c|c|c|c|}
\hline Age group & $\mathbf{n}$ & $\%$ of age & Male & Male \% & Female & Female \% \\
\hline$\leq 25$ & 17 & 4 & 8 & 1.9 & 9 & 2.1 \\
\hline $26-45$ & 231 & 54.4 & 118 & 27.8 & 113 & 26.6 \\
\hline $46-65$ & 156 & 36.7 & 93 & 21.9 & 63 & 14.8 \\
\hline$>65$ & 21 & 4.9 & 15 & 3.5 & 6 & 1.4 \\
\hline Total & 425 & 100 & 234 & 55.1 & 191 & 44.9 \\
\hline
\end{tabular}

Table 2: Characteristics of survey respondents $(n=425)$.

\begin{tabular}{|l|c|c|c|}
\hline \multicolumn{1}{|c|}{ Characteristics } & $\mathbf{n}$ & $\%$ \\
\hline Marital status & Married & 366 & 86.1 \\
\hline Unmarried & 59 & 13.9 \\
\hline Habitat & \multicolumn{2}{|l|}{} \\
\hline & Urban & 190 & 44.7 \\
\hline Semi-urban & 161 & 37.9 \\
\hline Rural & 74 & 17.4 \\
\hline
\end{tabular}

Education

\begin{tabular}{|c|c|c|}
\hline Illiterate & 30 & 7.1 \\
\hline Primary to $8^{\text {th }}$ grade & 93 & 21.9 \\
\hline Secondary & 71 & 16.7 \\
\hline Higher secondary & 122 & 28.7 \\
\hline Graduate and above & 109 & 25.6 \\
\hline
\end{tabular}

Occupation

\begin{tabular}{|c|c|c|}
\hline Unemployed/laborer/retired & 43 & 10.1 \\
\hline Homemaker & 125 & 29.4 \\
\hline Government services & 65 & 15.3 \\
\hline Private sector & 87 & 20.5 \\
\hline Business & 105 & 24.7 \\
\hline
\end{tabular}

Socio-economic status

\begin{tabular}{|c|c|c|}
\hline Poor & 145 & 34.1 \\
\hline Average & 140 & 32.9 \\
\hline Rich & 140 & 32.9 \\
\hline Duration of diabetes & 92 & 21.6 \\
\hline <5 years & 204 & 48.0 \\
\hline 5-10 years & 129 & 30.4 \\
\hline$>10$ years & &
\end{tabular}

Family history of diabetes

\begin{tabular}{|c|c|c|}
\hline Yes & 174 & 40.9 \\
\hline No & 137 & 32.2 \\
\hline I don't know & 114 & 26.8 \\
\hline Educational programs attended & 164 & 38.6 \\
\hline Attended once & 104 & 24.5 \\
\hline Attended regularly & 157 & 36.9 \\
\hline Never attended & & \multicolumn{2}{|l|}{} \\
\hline
\end{tabular}

was $11.06 \pm 3.17 \mathrm{mmol} / \mathrm{L}$ (range $4.80-19.80 \mathrm{mmol} / \mathrm{L}$ ) noted form the patients guide book provided by the hospital for routine checkups. 
Table 3: Distribution of comorbidities with diabetes among the survey respondents $(n=425)$.

\begin{tabular}{|c|c|c|c|}
\hline Co-morbidity & Total (\%) & Male (\%) & Female (\%) \\
\hline Respiratory illness (Asthma, Bronchitis, Pleurisy, Pneumonia, Seasonal flu, Diphtheria, Tuberculosis, Tonsillitis) & $87(20.5)$ & $59(13.9)$ & $28(6.6)$ \\
\hline Cardiovascular disease (Hypertension and heart disease) & $47(11.1)$ & $35(8.2)$ & $12(2.8)$ \\
\hline Renal disease (Chronic kidney disease, UTI) & $41(9.6)$ & $29(6.8)$ & $12(2.8)$ \\
\hline Pain (Back pain, Breast pain, Chest pain, Foot, Headache, Rheumatism, Toothache, Wrist pain) & $47(11.1)$ & $25(5.9)$ & $22(5.2)$ \\
\hline Cancer (Blood, Brain, Breast, Stomach) & $19(4.5)$ & $8(1.9)$ & $11(2.6)$ \\
\hline GIT diseases (Liver disease, Gall bladder stone, Appendicitis, Peptic ulcer disease) & $24(5.6)$ & $11(2.6)$ & $13(3.1)$ \\
\hline Nervous system disease (Neuropathy, paralysis, and psychosis) & $11(2.6)$ & $7(1.6)$ & $4(0.9)$ \\
\hline Foot ulcer & $6(1.4)$ & $4(0.9)$ & $2(0.5)$ \\
\hline Allergy & $18(4.2)$ & $8(1.9)$ & $10(2.4)$ \\
\hline Others (Thyroid disorder, Sexual weakness, Cystic ovary disease, Ear disease, Eye disease, Piles, fistula, hernia) & $19(4.5)$ & $11(2.6)$ & $8(1.9)$ \\
\hline None & $106(24.9)$ & $37(8.7)$ & $69(16.2)$ \\
\hline
\end{tabular}

Mean $\mathrm{HbA1c}$ level was $9.73 \pm 2.65 \%$ (range 3.8-16.7\%).

\section{Co-morbidities}

According to the patient complaint and reviewing the diagnosis from record file of patients about the co-morbidities along with diabetes, we found about $75 \%$ patients were suffering from comorbidities other than diabetes. One hundred and six (24.9\%) patients had no other diseases. We have grouped the diseases according to the systems affected and found that most of the patients were suffering from respiratory illnesses $(\mathrm{n}=87 ; 20.5 \%)$. Cardiovascular diseases particularly hypertension and renal diseases were also common too. More than eleven percent was suffering from different kinds of pain. Details are shown in Table 3 according to the gender distribution of co-morbidity. According to the table it is visible that males were more sufferers of co-morbidities than females.

\section{Practice score}

The maximum practice score was 27 . The mean score was 16.89 (95\% CI for mean 16.25-17.53) and Standard Deviation (SD) \pm 3.79 with a range of 3 to 27 . By categorizing the practice score into 4 categories such as poor, fair, good and very good according to the quartile of the scores and the finding was nearly $20 \%(n=84 ; 19.8 \%)$ participants scored good practice regarding diabetic complications and co-morbidities. Almost 30\% $(\mathrm{n}=120 ; 28.2 \%)$ participants possesses poor practice.

More than 95\% $(n=407)$ patients replied that the monitor their blood glucose on a regular basis and more than $85 \%$ patients follows their prescription regularly but only about $60 \%(n=243$; $57.2 \%)$ performs exercise daily to control diabetes. Less than $50 \%$ of respondents reported about regular feet examination. Periodical kidney examination were done by approximately $64 \%(n=271 ; 63.8 \%)$ respondents. Nineteen percent $(\mathrm{n}=80 ; 18.8 \%)$ of them were smokers and around $10 \%(\mathrm{n}=40 ; 9.4 \%)$ were former smokers.

Bivariate analysis reveals that practice score is also influenced by gender, habitat, marital status and education Table 4. Age had no significant influence on practice score of the respondents. Mean score of practice was higher among males $(P=<0.001)$, similarly mean score of practice was higher among married patients $(P=0.001)$. Urban habitats had better practice score than semi-urban and rural habitats $(P=<0.001)$. Patients who had education above higher secondary had better practice score $(P=0.001)$. Rich participants $(P=0.064)$ and patients with duration of diabetes more than 10 years $(P=0.089)$ had higher practice scores but it is not statistically significant. Family history of diabetes had significant influence on patients practice score $(P=<0.001)$. However other variables such as level of RBS and level of $\mathrm{HbA1C}$ had statistically significant influence on patients practice scores regarding complications of diabetes $(P=<0.001)$. Presence of co-morbidities was not associated with practice score but patients having good level of RBS and HBA1C had better practice score with significant association.

\section{Discussion}

Improvements in the health delivery system have evolved past few years with integrated fashion and continue to rise. Thus, health care delivery for diabetes and related co-morbidities and complications also changed remarkably across the country. This report provided an update of prevalent co-morbidities and important features of practices regarding care of diabetes and its complications among patients and its associated factors. Several studies have been carried out to identify prevalence of co-morbidities $[19,20]$ and practices regarding diabetes $[21,22]$. Therefore, no particular study found regarding co-morbidities and care practices of diabetic patients about the complications of diabetes. However, it was hard to compare our results with others.

While determining presence of co-morbidities in our selected group of diabetic patients, we found most of them were suffering from several respiratory illnesses, cardiovascular diseases particularly hypertension, nephropathy and neuropathy. These co-morbidities including others were also found prevalent in other study [19]. These commonly occurring co-morbidities in diabetic patients might be the consequence of hyperglycemia in some cases. These chronic conditions are important to not because they are common but they can cause high amount of economic burden and increased healthcare expenditure $[16,23,24]$.

Very few participant in this cohort possessed very good practice. Those small number of patients who were able to manage their health conditions to avoid further complications and dealing with co-morbidities. This figures are supported by other similar study in assessing practice for diabetes where researchers have found low level 
Table 4: Bivariate analysis for practices.

\begin{tabular}{|c|c|c|c|c|}
\hline \multirow{3}{*}{ Variables } & \multicolumn{4}{|c|}{ Practice score } \\
\hline & \multirow{2}{*}{$($ mean \pm SD) } & \multicolumn{2}{|c|}{$95 \% \mathrm{Cl}$} & \multirow{2}{*}{$P$ value } \\
\hline & & Lower & Upper & \\
\hline \multicolumn{5}{|c|}{ Age } \\
\hline$\leq 25$ & $15.88 \pm 2.26$ & 14.72 & 17.04 & \multirow{4}{*}{0.368} \\
\hline $26-45$ & $16.95 \pm 3.82$ & 16.46 & 17.45 & \\
\hline $46-65$ & $16.91 \pm 3.79$ & 16.31 & 17.51 & \\
\hline$>65$ & $16.85 \pm 4.49$ & 14.80 & 18.90 & \\
\hline \multicolumn{5}{|c|}{ Gender } \\
\hline Male & $17.48 \pm 3.67$ & 17.01 & 17.96 & \multirow{2}{*}{$<0.001$} \\
\hline Female & $16.16 \pm 3.81$ & 15.61 & 16.70 & \\
\hline \multicolumn{5}{|c|}{ Marital status } \\
\hline Married & $17.13 \pm 3.88$ & 16.73 & 17.53 & \multirow{2}{*}{$<0.001$} \\
\hline Unmarried & $15.38 \pm 2.12$ & 14.68 & 16.09 & \\
\hline \multicolumn{5}{|c|}{ Habitat } \\
\hline Urban & $17.53 \pm 3.71$ & 16.99 & 18.07 & \multirow{3}{*}{$<0.001$} \\
\hline Semi-urban & $15.98 \pm 3.07$ & 15.50 & 16.45 & \\
\hline Rural & $17.21 \pm 4.82$ & 16.09 & 18.33 & \\
\hline \multicolumn{5}{|c|}{ Education } \\
\hline Illiterate & $17.56 \pm 3.48$ & 16.26 & 18.86 & \multirow{5}{*}{0.001} \\
\hline Primary to $8^{\text {th }}$ grade & $16.95 \pm 4.44$ & 16.04 & 17.87 & \\
\hline Secondary & $16.15 \pm 3.80$ & 15.25 & 17.05 & \\
\hline Higher secondary & $16.08 \pm 3.08$ & 15.48 & 16.67 & \\
\hline Graduate and above & $18.03 \pm 3.45$ & 17.38 & 18.69 & \\
\hline \multicolumn{5}{|c|}{ Occupation } \\
\hline Unemployed/laborer/retired & $17.58 \pm 3.61$ & 16.46 & 18.69 & \multirow{5}{*}{0.087} \\
\hline Homemaker & $16.33 \pm 4.06$ & 15.61 & 17.05 & \\
\hline Government services & $17.15 \pm 3.56$ & 16.27 & 18.03 & \\
\hline Private sector & $16.44 \pm 3.69$ & 15.66 & 17.23 & \\
\hline Business & $17.47 \pm 3.66$ & 16.76 & 18.18 & \\
\hline \multicolumn{5}{|c|}{ Socio-economic status } \\
\hline Poor & $16.40 \pm 3.88$ & 15.76 & 17.03 & \multirow{3}{*}{0.064} \\
\hline Average & $16.84 \pm 3.91$ & 16.18 & 17.49 & \\
\hline Rich & $17.45 \pm 3.91$ & 16.68 & 18.03 & \\
\hline \multicolumn{5}{|c|}{ Duration of diabetes (years) } \\
\hline$<5$ years & $16.98 \pm 3.87$ & 16.18 & 17.79 & \multirow{3}{*}{0.089} \\
\hline $5-10$ years & $16.50 \pm 3.53$ & 16.01 & 16.99 & \\
\hline$>10$ years & $17.43 \pm 4.07$ & 16.72 & 18.14 & \\
\hline \multicolumn{5}{|c|}{ Family history of diabetes } \\
\hline Yes & $17.54 \pm 3.96$ & 16.95 & 18.13 & \multirow{3}{*}{$<0.001$} \\
\hline No & $17.26 \pm 3.62$ & 16.65 & 17.87 & \\
\hline I don't know & $15.44 \pm 3.34$ & 14.82 & 16.06 & \\
\hline \multicolumn{5}{|c|}{ Educational programs attended } \\
\hline Attended once & $15.73 \pm 3.11$ & 15.25 & 16.21 & \\
\hline Attended regularly & $16.67 \pm 3.36$ & 16.01 & 17.32 & $<0.001$ \\
\hline Never attended & $18.24 \pm 4.25$ & 17.57 & 18.91 & \\
\hline
\end{tabular}

\begin{tabular}{|c|c|c|c|c|}
\hline \multicolumn{5}{|c|}{ Consultation time by doctors } \\
\hline$<5$ minutes & $15.74 \pm 3.89$ & 14.81 & 16.67 & \multirow{3}{*}{0.005} \\
\hline 5-10 minutes & $16.90 \pm 3.83$ & 16.42 & 17.38 & \\
\hline$>10$ minutes & $17.62 \pm 3.43$ & 16.96 & 18.29 & \\
\hline \multicolumn{5}{|c|}{ Methods of treatment } \\
\hline Diet+Oral agents & $17.66 \pm 4.26$ & 16.62 & 18.79 & \multirow{4}{*}{0.070} \\
\hline Diet+Insulin & $16.85 \pm 3.71$ & 16.34 & 17.37 & \\
\hline Diet+Oral agents+Insulin & $16.67 \pm 3.63$ & 16.08 & 17.26 & \\
\hline None & $12.66 \pm 1.15$ & 9.79 & 15.53 & \\
\hline \multicolumn{5}{|c|}{ Monitoring blood glucose level } \\
\hline Self & $16.93 \pm 3.58$ & 15.02 & 18.84 & \multirow{3}{*}{0.999} \\
\hline Local pharmacy & $16.89 \pm 3.34$ & 16.26 & 17.51 & \\
\hline Hospital & $16.88 \pm 3.96$ & 16.43 & 17.34 & \\
\hline \multicolumn{5}{|c|}{ Use of herbal medication } \\
\hline Yes & $16.61 \pm 4.02$ & 15.86 & 17.37 & \multirow{2}{*}{0.370} \\
\hline No & $16.99 \pm 3.70$ & 17.57 & 17.40 & \\
\hline \multicolumn{5}{|c|}{ Random Blood Glucose(RBS) level } \\
\hline Good (4.4-7.8 mmol/L) & $19.29 \pm 3.53$ & 18.54 & 20.03 & \multirow{3}{*}{$<0.001$} \\
\hline Acceptable (7.9-11.1 mmol/L) & $16.65 \pm 3.95$ & 15.94 & 17.36 & \\
\hline Poor (> $11.1 \mathrm{mmol} / \mathrm{L})$ & $16.03 \pm 3.37$ & 15.57 & 16.48 & \\
\hline \multicolumn{5}{|c|}{ Glycemic control $(9.73 \pm 2.65 \%)$} \\
\hline Good $\left(\mathrm{HbA}_{1 \mathrm{c}}<7 \%\right)$ & $18.64 \pm 3.49$ & 17.86 & 19.42 & \multirow{3}{*}{$<0.001$} \\
\hline Acceptable $\left(\mathrm{HbA}_{1 \mathrm{c}} 7-8 \%\right)$ & $17.12 \pm 3.96$ & 16.19 & 18.04 & \\
\hline Poor $\left(\mathrm{HbA}_{1 \mathrm{c}}>8 \%\right)$ & $16.32 \pm 3.36$ & 15.88 & 16.76 & \\
\hline \multicolumn{5}{|c|}{ Co-morbidities } \\
\hline Present & $17.07 \pm 3.67$ & 16.66 & 17.48 & \multirow{2}{*}{0.084} \\
\hline Absent & $16.33 \pm 4.07$ & 15.55 & 17.12 & \\
\hline
\end{tabular}

of practice score [21].

The present study is in concordance with another study in terms of relationship between gender and practice score where male participant showed better level of practice [21]. In our study we also found that males scored better than females. The likelihood of good practice among male probably due to illiteracy, lack of selfempowerment and social status of females. Women are also given less priority for seeking health care and regular checkups. Marital status had significant association with practice. The finding was similar for other studies too $[21,26,28]$. This could be due to continuous support and care from spouse, therefore more attention must be given to the unmarried or divorced patients during educational program or physicians counselling. Urban habitats scored better in practice. Hence it is the result of better health care facilities available in urban areas.

Educational level was associated factor for practices regarding diabetes in a study [26]. In our study, educational status had significant association with good practices. This might be due to educated participants are able to read necessary information easily compared to the illiterates. A recent study in Iran, Niroomand et al. found positive significant correlation between disease duration and complication practice level [25]. But other study revealed that 
participant suffering from diabetes less than five years were more involved in practicing properly to minimize consequences [27]. In our study, duration of diabetes was not significant factor for practice but those who were suffering more from diabetes showed better level of practice. This may be due to regular counselling and contact with the health professionals. Another study in Iran, reported having had no effect of duration of diabetes with practice regarding diabetes foot care which may indicate the usefulness of patient education in healthcare facility [28].

Attending educational program was significantly associated practices in present study but interestingly who attended educational programs had lower practice score than who never attended. This may require further investigation to find out the related factors. It is important to know that providing education to the vulnerable groups can become a cost-effective public health strategy [29]. Having positive family history of diabetes had positive influence on patient's practice which contradicts the finding of other study [26]. This is important to know that receiving information from family with chronic disease might influence on patients attitude and daily practice which can be a good source of information [30] but such informal sources are not always reliable. Duration of time for consultation was significantly associated with practice. Participants scored better who had consultation time by physicians more than ten minutes than the other groups. This finding is also concord with other findings [21,31]. Continuous counselling and regular visit for health care facilities might be a contributing factor. Therefore duty goes to physician to help patients for better understanding of their disease process and possible complications for better self care and management.

Random Blood Sugar (RBS) level and HbA1C level both were significantly associated with practice score. But this finding contradicts the finding of others [26]. This could be explained as better practicing for management of diabetes and its related complication led to better level of RBS and $\mathrm{HbA1C}$ and those scored better in practice selection of the study.

This study can help in providing necessary information about common co-morbidities and specific variables for practices which could play in preventing diabetic complications, in addition, to help plan larger study design addressing the challenges picked out in this project. As our study was based on outpatients in one hospital, the results may not be typical of all diabetic patients in Bangladesh. Evidence suggests that training and self-management is a core part of the treatment of diabetes [32].

Patient education is the most constructive track that can assist in early detection, lessen the complications and management of diabetes 2 [33]. This study re-emphasizes the fact that properly designed and implemented education and other support programs to diabetics would be more fruitful. Provided complete information on patient's characteristics healthcare professionals can effectively design their care processes according to the patients' needs [34] for better practices regarding co-morbidities and complications of diabetes.

\section{Conclusion}

Several co-morbidities have been observed in our surveyed cohort. Most common co-morbidities were respiratory illnesses, Hypertension and other cardiac problems, pain and chronic kidney diseases along with diabetes. Our data has also provided an insight into some relationships between respondents' variables and practices. Poor practice level were found in this surveyed community. Age group, marital status, habitats, educational level, family history, educational program and duration of treatment were the most significant associated factor for practice. Physicians active participation and time for providing structured education and counseling for patients may bring better therapeutic outcome and lessen complications of diabetes or other co-morbid conditions. Self management of patients is imperative to improve health status of diabetic patients.

\section{References}

1. Kuller LH. Dietary fat and chronic diseases: epidemiologic overview. J Am Diet Assoc. 1997; 97: 9-15.

2. Wild S, Roglic G, Green A, Sicree R, King H. Global prevalence of diabetes: estimates for the year 2000 and projections for 2030. Diabetes care. 2004; 27: 1047-1053

3. Lozano R, Naghavi M, Foreman K, Lim S, Shibuya K, Aboyans V, et al. Global and regional mortality from 235 causes of death for 20 age groups in 1990 and 2010: a systematic analysis for the Global Burden of Disease Study 2010. Lancet. 2012; 380: 2095-2128.

4. World Health Organization. Global Health Estimates: Daly by Cause, Age and Sex, 2000-2012. WHO. 2014

5. WHO Mortality Database. World Health Organization. 2016

6. Druss BG, Marcus SC, Olfson M, Tanielian T, Elinson L, Pincus HA. Comparing the national economic burden of five chronic conditions. Health Aff (Millwood). 2001; 20: 233-241.

7. Wolff JL, Starfield B, Anderson G. Prevalence, expenditures, and complications of multiple chronic conditions in the elderly. Arch Intern Med. 2002; 162: 2269-2276.

8. Saquib N, Saquib J, Ahmed T, Khanam MA, Cullen MR. Cardiovascular diseases and type 2 diabetes in Bangladesh: a systematic review and metaanalysis of studies between 1995 and 2010. BMC Public Health. 2012; 12: 434.

9. International Diabetes Federation. IDF Diabetes Atlas- $7^{\text {th }}$ Edition. 2015.

10. Hussain A, Rahim MA, Azad Khan AK, Ali SMK, Vaaler S: Type 2 diabetes in rural and urban population: diverse prevalence and associated risk factors in Bangladesh. Diabet Med. 2005; 22: 931-936.

11. Davis SN. Insulin, oral hypoglycemic agents and the pharmacology of the endocrine pancreas. In: Brunton LL, Lazo JS, Parker KL editors. Goodman \& Gilman's: The Pharmacological basis of therapeutics 11th edition, New York McGraw-Hill, 2006: 1613-1645.

12. Roglic G, Unwin N, Bennett PH, Mathers C, Tuomilehto J, Nag S, et al. The burden of mortality attributable to diabetes: realistic estimates for the year 2000. Diabetes care. 2005; 28: 2130-2135.

13. Vijan S, Stevens DL, Herman WH, Funnell MN, Staniford CJ. Screening, prevention, counseling, and treatment for the complications of type // diabetes mellitus. Putting evidence into practice. J Gen Intern Med. 1997; 12: 567-580.

14. Eastman RC, Javitt JC, Herman WH, Dasbach EJ, Copley-Merriman C, Maier W, et al. Model of complications of NIDDM. II. Analysis of the health benefits and cost-effectiveness of treating NIDDM with the goal of normoglycemia. Diabetes Care. 1997; 20: 735-744.

15. Larsson D, Lager I, Nilsson PM. Socio-economic characteristics and quality of life in diabetes mellitus- relation to metabolic control. Scand J Public Health. 1999; 2: 101-105.

16. US Department of Health and Human Services. Managing Multiple Chronic Conditions: A Strategic Framework-Optimum Health and Quality of Life for Individuals with Multiple Chronic Conditions. Washington, DC: HHS; 2010.

17. Lochner KA, Cox CS. Prevalence of multiple chronic conditions among Medicare beneficiaries, United States, 2010. Prev Chronic Dis. 2013; 10: E61. 
18. Kirigia JM, Sambo HB, Sambo LG, Barry SP. Economic burden of diabetes mellitus in the WHO African region. BMC Int Health Hum Rights. 2009; 9: 6.

19. KM MR, Anandhasayanam A, Kannan S, Noon MSD. Prevalence of Comorbidities in Type 2 Diabetes Mellitus Patients, the Awareness Level and the Impact of Pharmacist's Patient Education Program. International Journal of Pharma Research \& Review. 2015; 4: 11-20.

20. Lin PJ, Kent DM, Winn A, Cohen JT, Neumann PJ. Multiple chronic conditions in type 2 diabetes mellitus: prevalence and consequences. Am J Manag Care. 2015; 21: e23-34

21. Feleke SA, Alemayehu CM, Adane HT. Assessment of the level and associated factors with knowledge and practice of Diabetes Mellitus among Diabetic Patients attending at FelegeHiwot Hospital, Northwest Ethiopia Clinical Medicine Research. 2013; 2: 110-120.

22. Saleh F, Mumu SJ, Ara F, Begum HA, Ali L. Knowledge and self-care practices regarding diabetes among newly diagnosed type 2 diabetics in Bangladesh: a cross-sectional study. BMC public health. 2012; 12: 1112

23. Boyd CM, Darer J, Boult C, Fried LP, Boult L, Wu AW. Clinical practice guidelines and quality of care for older patients with multiple comorbid diseases: implications for pay for performance. JAMA. 2005; 294: 716-724.

24. Tinetti ME, Fried TR, Boyd CM. Designing health care for the most common chronic condition--multimorbidity. JAMA. 2012; 307: 2493-2494.

25. Niroomand M, Ghasemi SN, Karimi-Sari H, Kazempour-Ardebili S, Amir $\mathrm{P}$, Khosravi $\mathrm{MH}$. Diabetes Knowledge, Attitude and Practice (KAP) study. Diabetes Metab Syndr. 2015; 10: S114-119.

26. Al-Maskari F, El-Sadig M, Al-Kaabi JM, Afandi B, Nagelkerke N, Yeatts KB. Knowledge, attitude and practices of diabetic patients in the United Arab Emirates. PLoS One. 2013; 8: e52857.
27. Ahmed MU, Seriwala HM, Danish SH, Khan AM, Hussain M, Husain M, et al Knowledge, Attitude, and Self Care Practices Amongsts Patients with Type 2 Diabetes in Pakistan. Glob J Health Sci. 2016; 8: 1-8.

28. Khamseh ME, Vatankhah N, Baradaran HR. Knowledge and practice of foot care in Iranian people with type 2 diabetes. Int Wound J. 2007; 4: 298-302.

29. Balagopal P, Kamalamma N, Patel TG, Misra R. A community-based diabetes prevention and management education program in a rural village in India. Diabetes care. 2008; 31: 1097-1104.

30. Hawthorne K, Tomlinson S. Pakistani moslems with Type 2 diabetes mellitus: effect of sex, literacy skills, known diabetic complications and place of care on diabetic knowledge, reported self-monitoring management and glycaemic control. Diabetic Med. 1999; 16: 591-597.

31. Adibe M, Aguwa CN, Ukwe C, Okonta JM, Udeogaranya P. Diabetes selfcare knowledge among type 2 diabetic outpatients in South-Eastern Nigeria. Int J Drug Dev Res. 2009; 1: 85-104.

32. Sousa VD, Zauszniewski JA. Toward a theory of diabetes self-care management. Journal of Theory Construction \& Testing. 2005; 9: 61-67.

33. Mazzuca SA, Moorman NH, Wheeler ML, Norton JA, Fineberg NS, Vinicor F et al. The diabetes education study: a controlled trial of the effects of diabetes education. Diabetes care. 1986; 9: 1-10.

34. Gåfvels C, Lithner F, Börjeson B. Living with diabetes: relationship to gender, duration and complications. A survey in northern Sweden. Diabet Med. 1993; 10: 768-773.
Austin J Public Health Epidemiol - Volume 4 Issue 2 - 2017 ISSN : 2381-9014 | www.austinpublishing group.com Rahaman et al. () All rights are reserved
Citation: Rahaman KS, Majdzadeh R, Naieni KH and Raza O. Comorbidities and Care Practices of Diabetic Patients. Austin J Public Health Epidemiol. 2017; 4(2): 1059 